Revista Eureka sobre Enseñanza y Divulgación de las Ciencias

ISSN: 1697-011X

revista.eureka@uca.es

Universidad de Cádiz

España

\title{
Visibilizar el pensamiento a través de la enseñanza de las ciencias experimentales en Educación Infantil
}

Gil Puente, Cristina; Manso Bartolomé, Adrián

Visibilizar el pensamiento a través de la enseñanza de las ciencias experimentales en Educación Infantil

Revista Eureka sobre Enseñanza y Divulgación de las Ciencias, vol. 19, núm. 1, 2022

Universidad de Cádiz, España

Disponible en: https://www.redalyc.org/articulo.oa?id=92068491001

DOI: https://doi.org/10.25267/Rev_Eureka_ensen_divulg_cienc.2022.v19.i1.1201 


\section{Visibilizar el pensamiento a través de la enseñanza de las ciencias experimentales en} Educación Infantil

\section{Making thinking visible through teaching experimental science in early childhood education students}

Cristina Gil Puente

Departamento de Didáctica de las Ciencias Experimentales. Universidad de Valladolid. Segovia, España

cristina.gil.puente@uva.es

iD https://orcid.org/0000-0001-5794-5564

Adrián Manso Bartolomé

Facultad de educación. Universidad de Valladolid. Segovia,

España

adrianmansob@gmail.com

iD https://orcid.org/0000-0002-0786-6224
DOI: https://doi.org/10.25267/

Rev_Eureka_ensen_divulg_cienc.2022.v19.i1.1201

Redalyc: https://www.redalyc.org/articulo.oa?

$\mathrm{id}=92068491001$
Recepción: 13 Mayo 2020

Revisado: 22 Agosto 2020

Aprobación: 18 Julio 2021

\section{Resumen:}

El presente trabajo tiene como objetivo principal visibilizar el pensamiento del alumnado de educación infantil a través de la enseñanza de las ciencias experimentales. Para ello se ha desarrollado e implementado una propuesta didáctica centrada en la temática del conocimiento y concienciación del uso y cuidado del agua, utilizando como principales metodologías el aprendizaje basado en problemas y las rutinas de pensamiento. Esta intervención didáctica ha permitido comprobar la progresiva consecución de máximos niveles de logro en el desarrollo de los movimientos de pensamiento seleccionados para la propuesta. Se obtiene como principal conclusión la importancia de enseñar a pensar, puesto que la etapa de educación infantil es el momento ideal para comenzar a hacer visible el pensamiento del alumnado.

Palabras Clave: educación infantil, pensamiento visible, ciencias experimentales, rutinas de pensamiento, movimientos de pensamiento y conocimiento y cuidado del agua.

\section{Abstract:}

The main aim of this paper is to make thinking visible in early childhood education students through experimental science. To do so, a teaching proposal has been developed and taken to practice, focused on the consciousness, raising and knowledge of the uses and care of water. It is based on problem-based learning and thinking routines used as methodologies. This didactic intervention allowed us to check the ongoing accomplishment of advanced achievement levels in the development of the thinking movements selected for this proposal. As a result, the main conclusion obtained is the importance of teaching how to think, since early childhood education is the perfect moment to start making thinking visible in students.

KEYWORDS: early childhood education, visible thinking; experimental science; thinking routines; thinking movements and knowledge and water care.

\section{INTRODUCCIÓN}

Uno de los principales motivos por el cual se ha querido llevar a cabo esta propuesta didáctica es para dar a conocer el valor educativo y de aprendizaje que tienen las ciencias experimentales en la etapa de educación infantil. Vega (2012) y Cabell (2011) explican como a través de la experimentación se le otorga al niño un papel protagonista en el que se encuentra en constante manipulación y vivenciación de la práctica experimental. 
Estos mismos autores comprenden la etapa de educación infantil como un periodo perfecto para iniciar en el alumnado la necesidad de experimentar para conocer su entorno más cercano y comprender la realidad que les rodea.

Asimismo, se entiende que el uso de la experimentación científica en el ciclo de infantil con el fin de conocer el contexto más próximo del niño, desarrolla aprendizajes y conocimientos. En este proceso de aprendizaje se desarrolla el pensamiento del alumnado, puesto que se va a encontrar en la necesidad de desarrollar movimientos del propio pensamiento como razonar, evidenciar, describir, construir interpretaciones, captar lo esencial etc.

Por este motivo se deduce que para aplicar un buen uso de las ciencias experimentales en nuestro alumnado, es imprescindible comenzar a hacer visible su pensamiento. A través del proyecto denominado Pensamiento Visible (Richhart, Church y Morrison 2014) se ha podido apreciar la importancia y de los beneficios que se obtienen en la práctica educativa al hacer visible el pensamiento del alumnado. Para ello utilizamos las rutinas de pensamiento como instrumentos.

Poder aplicar una intervención didáctica que se fundamenta en el pensamiento visible y las ciencias experimentales en la etapa de educación infantil supuso un gran reto, debido a que se consideran dos elementos que interrelacionados adecuadamente generan un gran aprendizaje y conocimiento a la vez que el alumnado es capaz de visualizar su pensamiento y comprender los pasos a seguir o movimientos que ha desarrollado para conseguir ese pensamiento.

En este trabajo se pretende conocer los beneficios de la puesta en práctica de una intervención didáctica en la que se trabaja el conocimiento y concienciación del cuidado del agua, fomentando en el alumnado la comprensión de su contexto y realidad más próxima a través de la experimentación científica y el pensamiento visible. Teniendo en cuenta esta premisa, los principales objetivos de nuestro trabajo son los siguientes:

- Fomentar en el alumnado de educación infantil el conocimiento de su entorno más cercano a través de la experimentación científica y el pensamiento visible.

- Analizar cómo influye la utilización de rutinas de pensamiento en el aprendizaje de las ciencias experimentales en educación infantil.

- Visibilizar el pensamiento del alumnado a través de la enseñanza de las ciencias experimentales.

\section{FUNDAMENTACIÓN TEÓRICA}

\section{Cultura de pensamiento}

Para Swartz, Costa, Beyer, Reagen, y Kallick (2015) pensar es "nuestra forma de tocar el instrumento del conocimiento" (p.8). Estos autores defienden que el pensamiento es la forma de ponerse en contacto con el conocimiento y utilizarlo para poder comprender el mundo que nos rodea. Si no tocamos el pensamiento el conocimiento quedará inmovilizado, siendo inservible e intuitivo.

Todo ser humano tiene la capacidad de pensar, pero en la mayoría de las ocasiones ese pensamiento es invisible y se realiza de forma inconsciente e intuitiva (Perkins 2008). Esto provoca que habitualmente se encuentren problemas o situaciones que invitan a pensar y no se tenga capacidad de resolución (Perkins y Tishman 2001).

El alumnado de educación infantil aprende de su entorno más próximo y de la cultura que les rodea diariamente. Para Perkins (1997) la cultura del pensamiento debe formar parte del aire en el aula, es decir, se debe enseñar al alumnado a pensar para que visibilizar su pensamiento sea un elemento más de la clase. Esto les facilitará su aprendizaje y los estudiantes tendrán la capacidad de resolver situaciones de dificultad más favorablemente. Como apuntan Tishman, Perkins y Jay (1994) “el propósito de enseñar a pensar es el 
de preparar a los alumnos para que, en el futuro, puedan resolver problemas con eficacia, tomar decisiones bien meditadas y disfrutar de toda una vida de aprendizaje" (p. 13).

Ritchhart (2015) muestra cómo la cultura de pensamiento se forma en aquellos lugares donde el pensamiento tanto individual como colectivo es valorado y se hace visible. Para poder generar una cultura de pensamiento, este mismo autor propone ocho fortalezas (ver figura 1) que las define como "herramientas que tenemos para transformar la cultura de la escuela y el aula" (p.10).

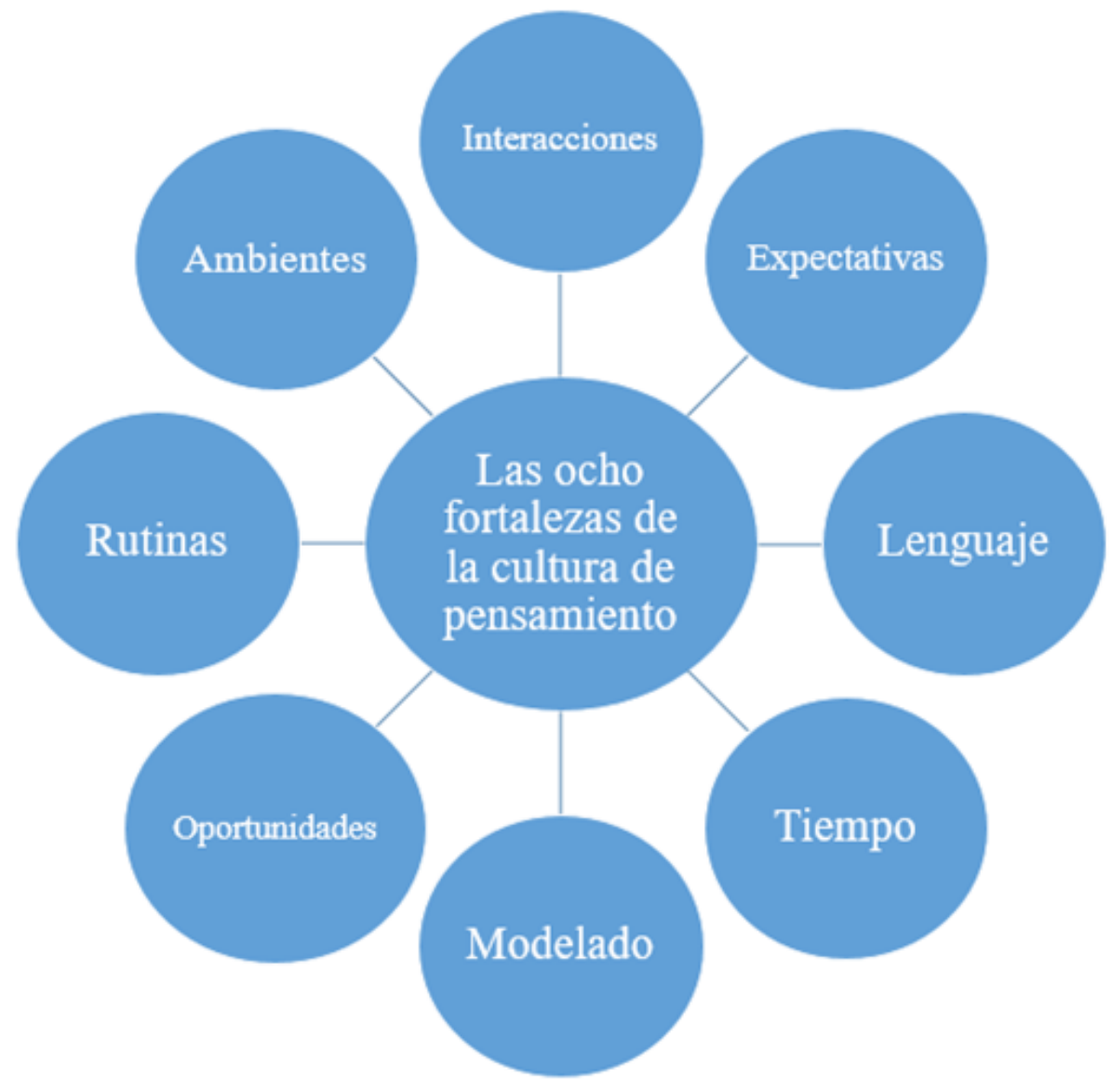

FIGURA 1

Las 8 fortalezas de la cultura de pensamiento

Esquema de elaboración propia a partir de Ritchhart (2015)

\section{Pensamiento visible y movimientos del pensamiento}

El origen del pensamiento visible se puede encontrar en Salmon (2009) donde se narra cómo un grupo de investigadores del Project Zero de la Harvard Graduate School of Education comenzaron un proyecto de investigación que tiene por nombre Pensamiento Visible. Desde este proyecto se pretende visibilizar el pensamiento haciendo conscientes a los alumnos de su pensamiento para que puedan expresarlo y compartirlo, lo que facilita su aprendizaje (Ritchhart y Perkins 2008).

Salmon (2015) define el pensamiento visible como:

Un enfoque, basado en investigaciones, que integra el desarrollo del pensamiento en el niño a través de las distintas disciplinas. El pensamiento visible crea disposiciones para pensar, entre otras: la curiosidad, la comprensión y la creatividad. No se centra exclusivamente en las destrezas del pensamiento, sino en las oportunidades para usar el pensamiento (p.90). 
Por otro lado, Tishman y Palmer (2005) afirman que el pensamiento visible "se refiere a cualquier tipo de representación observable que documente y apoye el desarrollo de las ideas, preguntas, razones y reflexiones en desarrollo de un individuo o grupo" (p.2). El uso de herramientas como mapas conceptuales, tablas, diagramas, listas, o rutinas, fomentan el desarrollo del pensamiento debido a que revelan las ideas que tienen los alumnos mientras piensan e interpretan un determinado aspecto o tema.

Como manifiestan Morales y Restrepo (2015) es fundamental que el pensamiento del niño y de las personas se encuentren reflejados y se hagan visibles, si esto no sucede generaremos un pensamiento inconsciente, donde las ideas pueden caer en el olvido o no seguir una estructura lógica. Además, según Perkins (2008) es necesario hacer visible el pensamiento del alumnado porque así podrán ser conscientes de sus hechos, teniendo una mayor capacidad de comprensión y reflexión que les hará mejorar. Por lo tanto, hacer visible el pensamiento es la manera más adecuada de que el alumnado comprenda qué es el pensamiento, puesto que lo entienden y lo visualizan.

Por otra parte, Ritchhart, Church y Morrison (2011) junto con la ayuda de otros investigadores del Project Zero, han creado una serie de movimientos de pensamiento que son fundamentales para indagar en el razonamiento y comprensión del alumnado, pudiendo hacer así visible su pensamiento (ver figura 2). 


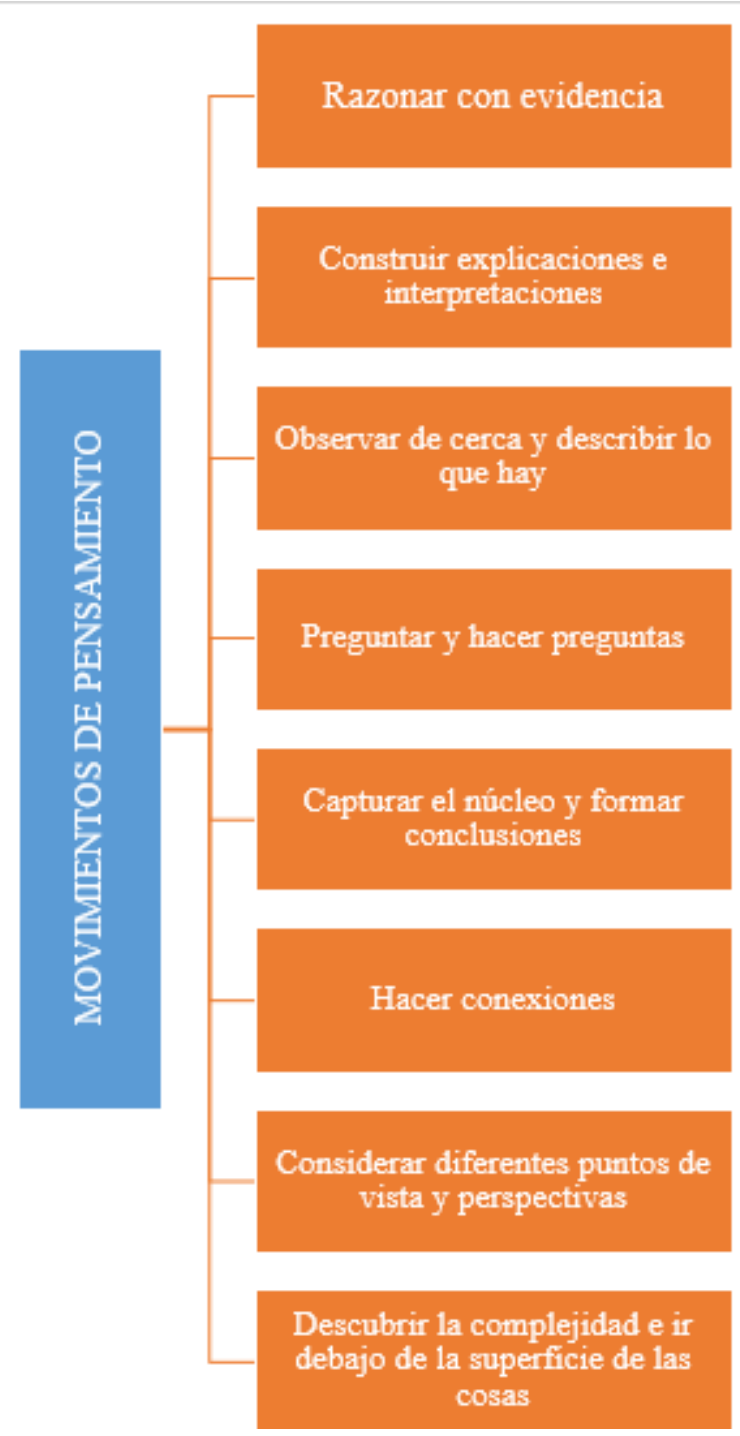

FIGURA 2

Movimientos del pensamiento

Esquema elaboración propia a partir de Ritchhart et al. (2011)

La consecución de estos ochos movimientos de pensamiento hará que los alumnos adquieran un alto grado de comprensión y de razonamiento. Pero para poder conseguir el desarrollo de estos movimientos en el pensamiento del estudiante, y por consiguiente hacer visible su pensamiento, se necesitan unos recursos o medios que lo hagan posible como son las rutinas de pensamiento.

\section{Rutinas de pensamiento visible}

Ritchhart y Perkins (2008) explican cómo al desarrollar el proyecto de investigación del Pensamiento Visible crearon una serie de estrategias organizadas y estructuras que serán el medio por el cual se podrá conseguir una cultura de pensamiento en el aula. Estas son las llamadas rutinas de pensamiento.

Para Sarradelo (2012) las rutinas de pensamiento son "unos patrones cognitivos muy sencillos, construidos por una serie de preguntas creativas o afirmaciones abiertas, desplegadas en pasos fáciles de aprender, fáciles de recordar, que se van interiorizando a través de una repetición sistemática” (p.18.). 
Se puede decir que las rutinas son el motor del pensamiento debido a que provocan que el pensamiento se haga visible y se comparta, facilitan que el alumnado pueda razonar, reflexionar y justificar aquello que haya aprendido o explorado. Mediante las rutinas se consigue que los estudiantes piensen más allá de lo que conocen, mediante la realización de cuestiones, la interrelación de ideas o conectar lo que antes sabían con lo que saben ahora (Tishman y Palmer 2005).

Para comprender cómo se pueden utilizar las rutinas de pensamiento en el aula, Ritchhart et al. (2014) proponen tres perspectivas de uso:

a) Como herramientas: son instrumentos que promueven los diferentes movimientos de pensamiento. Es importante seleccionar aquel movimiento de pensamiento que se quiera desarrollar en el alumnado y luego elegir la rutina de pensamiento específica que sirva como herramienta.

Las rutinas de pensamiento operan como herramientas de pensamiento, deben ser útiles tanto a los estudiantes como a los docentes. En lugar de ser simplemente actividades que ayudan a los docentes a enganchar a los estudiantes de manera activa, las rutinas de pensamiento son herramientas que los estudiantes pueden utilizar para apoyar su propio pensamiento (p.87).

b) Como estructuras: se componen de pasos estructurados y organizados "que actúan como un andamiaje natural que lleva a los estudiantes a niveles cada vez más altos y sofisticados de pensamiento”. (p.88)

c) Como patrones de comportamiento: tienen un carácter variable y flexible, esto permite al docente adaptarlas al contexto de su aula, a sus objetivos y enseñanzas.

Estas herramientas se vuelven flexibles en lugar de rígidas y constantemente evolucionan a medida que se utilizan. Los docentes pueden adaptar las rutinas para conseguir un mejor funcionamiento dependiendo de multitud de variables. Por ejemplo, el grado de evolución, la temática, el movimiento de pensamiento a conseguir etc.

Las rutinas de pensamiento se agrupan en tres grandes categorías, la primera corresponde a rutinas que se utilizan para presentar y explorar ideas, la segunda categoría tiene como uso principal sintetizar y organizar ideas y la tercera sirve para explorar las ideas más profundamente. A continuación, en las tablas 1, 2 y 3 se presentan las rutinas seleccionadas para llevar a cabo en este trabajo y la categoría a la que pertenecen:

TABLA 1

Rutina de pensamiento ver-pensar-preguntarse.

\begin{tabular}{|l|l|}
\hline \multicolumn{2}{|l|}{ RUTINA DE PENSAMIENTO: VER-PENSAR-PREGUNTARSE } \\
\hline Categoría & Rutinas para presentar y explorar ideas \\
\hline Propósito & $\begin{array}{l}\text { En esta rutina se da gran importancia a la observación para poder dar el paso hacia la } \\
\text { interpretación y el pensamiento. Además, es una rutina muy favorecedora para comenzar } \\
\text { una intervención educativa, debido a que posibilita el surgimiento de nuevas preguntas que } \\
\text { guíen la futura indagación. }\end{array}$ \\
\hline Pasos & $\begin{array}{l}1^{\circ} \text { Prepararse } \\
2^{\circ} \text { Ver } \\
3^{\circ} \text { Pensar } \\
4^{\circ} \text { Preguntarse } \\
5^{\circ} \text { Compartir el pensamiento }\end{array}$ \\
\hline $\begin{array}{l}\text { Consejos para } \\
\text { la puesta en } \\
\text { práctica }\end{array}$ & $\begin{array}{l}\text { 2. Estimar gran parte del tiempo de la rutina a la observación, puesto que es la base para } \\
\text { generar seguidamente unas adecuadas interpretaciones y preguntas. }\end{array}$ \\
& $\begin{array}{l}\text { 3. Las interpretaciones del docente deben servir para guiar el aprendizaje y puede realizar } \\
\text { comentarios como un estudiante más. } \\
\text { de tratarse como un error, pues puede generar cohibiciones e inhibición. }\end{array}$ \\
\hline
\end{tabular}


TABLA 2

Rutina de pensamiento el titular

\begin{tabular}{|l|l|}
\hline \multicolumn{2}{|l|}{ RUTINA DE PENSAMIENTO: EL TITULAR } \\
\hline Categoría & Rutinas para sintetizar y organizar ideas \\
\hline Propósito & $\begin{array}{l}\text { El principal fin de esta rutina es que alumno identifique la esencia de la intervención } \\
\text { educativa, donde para ello tendrá que reflexionar y sintetizar en el desarrollo de la rutina. } \\
\text { También es una rutina muy favorecedora para compartir el pensamiento, debido a que cada } \\
\text { alumno expone al resto de la clase su titular pudiendo generar así multitud de } \\
\text { razonamientos y de aprendizajes. }\end{array}$ \\
\hline Pasos & $\begin{array}{l}1^{\circ} \text { Prepararse } \\
2^{\circ} \text { Escribir un titular } \\
3^{\circ} \text { Compartir su pensamiento } \\
4^{\circ} \text { Invitar a seguir compartiendo }\end{array}$ \\
\hline $\begin{array}{l}\text { Consejos para } \\
\text { la puesta en docentes deben crear oportunidades y dar libertad al alumnado para que cree por el } \\
\text { en }\end{array}$ & $\begin{array}{l}\text { mismo su titular. Por lo tanto, durante la sesión no debemos enmarcarles aquello que es } \\
\text { 2. Hay que invitar al alumno a ir más allá de la propia temática, centrándose en las ideas y } \\
\text { elementos centrales. } \\
\text { 3. El docente puede guiar al estudiante a través de cuestiones, preguntándole qué historia } \\
\text { hay detrás de ese titular, o por qué han escogido este titular y no otro, relación de hechos } \\
\text { con palabras etc. }\end{array}$ \\
\hline
\end{tabular}

Elaboración propia a partir de Ritchhart et al. (2014)

TABLA 3

Rutina de pensamiento antes pensaba...ahora pienso

\begin{tabular}{|l|l|}
\hline RUTINA DE PENSAMIENTO: ANTES PENSABA...AHORA PIENSO \\
\hline Categoría & Rutinas para sintetizar y organizar ideas \\
\hline Propósito & $\begin{array}{l}\text { Esta rutina ayuda a los alumnos a explorar nuevos conocimientos y a reflexionar cómo ha } \\
\text { cambiado su pensamiento después de cualquier intervención didáctica llevada a cabo. Es } \\
\text { una rutina útil para consolidar nuevos aprendizajes y para que el alumno justifique con } \\
\text { argumentos sólidos cómo su pensamiento ha ido evolucionando y cambiando. }\end{array}$ \\
\hline Pasos & $\begin{array}{l}1^{\circ} \text { Prepararse } \\
2^{\circ} \text { Fomentar la reflexión individual } \\
3^{\circ} \text { Compartir el pensamiento }\end{array}$ \\
\hline $\begin{array}{l}\text { Consejos para } \\
\text { práctica }\end{array}$ & $\begin{array}{l}\text { 1. Esta rutina es ideal para hacer conscientes y dejar constancia al alumnado cómo a través } \\
\text { haciéndole consciente de su progresión y evolución. } \\
\text { 2. Al ser una rutina abierta y muy personal, como docentes no debemos buscar respuestas } \\
\text { cerradas y concretas, sino todo lo contrario, respuestas abiertas, argumentadas y reflexivas. } \\
\text { 3. Para poder realizar esta rutina adecuadamente es necesario que el alumnado tenga cierta } \\
\text { base con la que sustentarse, por lo que aconsejamos no usarla al principio de la unidad } \\
\text { didáctica. }\end{array}$ \\
\hline
\end{tabular}

Elaboración propia a partir de Ritchhart, et al. (2014) 


\section{MÉTodo}

\section{Participantes y contexto}

La intervención didáctica llevada a cabo fue realizada en un colegio de educación infantil y primaria (CEIP). Los alumnos que han sido partícipes de la propuesta de intervención didáctica se encuentran en el tercer curso del segundo ciclo de Educación Infantil, teniendo edades de 5 y 6 años. Se cuenta con un grupo de 13 estudiantes (7 niños y 4 niñas), y el número de docentes participantes ha sido de 2 . La elaboración de la propuesta se ha fundamentado curricularmente en el DECRETO 122/2007, de 27 de diciembre, por el que se establece el currículo del segundo ciclo de la educación infantil en la Comunidad de Castilla y León.

Aunque es un grupo no muy numeroso, dentro del aula existe una gran diversidad cultural, donde cada alumno proviene de países con unas costumbres, tradiciones e ideas diversas y variadas. Del número total de alumnos 7 son de origen marroquí, 3 de nacionalidad española (uno de ellos de etnia gitana), finalizando con una alumna de origen polaco y 2 alumnos latinoamericanos.

\section{Sesiones de aprendizaje de la propuesta didáctica}

La metodología activa elegida ha sido el aprendizaje basado en problemas, Torp y Sage (1999) explican el aprendizaje basado en problemas como una práctica pedagógica que tiene como fin resolver de una manera organizada y estructurada los problemas que se muestran en el mundo real. El uso de esta metodología activa junto a la aplicación de las rutinas de pensamiento van a permitir generar situaciones organizadas donde el alumnado pueda visibilizar su pensamiento, a la vez que va a permitir justificar, profundizar y cuestionar las actividades experimentales realizadas en la propuesta didáctica (Salmon 2015).

Este método de aprendizaje es muy apropiado para trabajar las ciencias experimentales en el ciclo de infantil, puesto que el alumnado tiene que ser capaz de resolver problemas de manera grupal adquiriendo un alto grado de autonomía. Estos deberán de analizar el problema, ofrecer una serie de hipótesis, ponerse de acuerdo en la asignación de tareas y obtener una serie razonamientos. Una vez resuelto problema tendrá que presentar al gran grupo los resultados y conclusiones obtenidos en el proceso de la resolución del problema (Briones y Gómez 2016).

Todas las sesiones de aprendizaje comienzan con un problema o reto propuesto por la mascota de la unidad didáctica Gotín (creada ad hoc) que los alumnos deberán resolver en pequeños grupos, adquiriendo el rol de científicos (ver tabla 4). A través del proceso de enseñanza- aprendizaje explicado al inicio de este apartado, se fomenta la necesidad en el alumnado de experimentar para conocer su entorno más cercano (Aymerich, Puig y Blanch 1999; Cabell 2011; Vega 2012), a la vez que se genera conocimiento, actitudes de respeto y cuidado del agua. Destacar que a día de hoy en las bases de datos de las revistas científicas más reconocidas, no se han encontrado propuestas didácticas y estudios similares donde se haga hincapié en visibilizar el pensamiento a través de la enseñanza de las ciencias experimentales en educación infantil. 
TABLA 4

Sesiones de aprendizaje

\begin{tabular}{|c|c|c|c|c|}
\hline $\begin{array}{l}\text { Sesión de } \\
\text { aprendizaje }\end{array}$ & $\begin{array}{l}\text { Contenido } \\
\text { principal }\end{array}$ & $\begin{array}{l}\text { Actividad experimental } \\
\text { principal }\end{array}$ & $\begin{array}{l}\text { Rutina de } \\
\text { pensamiento }\end{array}$ & $\begin{array}{l}\text { Movimientos de } \\
\text { pensamiento }\end{array}$ \\
\hline $\begin{array}{l}\text { Sesión 1: } \\
\text { ¿Conocemos } \\
\text { cómo es el } \\
\text { agua? }\end{array}$ & $\begin{array}{l}\text { Descubrimiento } \\
\text { de las } \\
\text { propiedades del } \\
\text { agua (incolora, } \\
\text { inodora e } \\
\text { insípida). }\end{array}$ & $\begin{array}{l}\text { Se utilizan los sentidos } \\
\text { humanos. E1 alumnado } \\
\text { debe ver, oler, tocar y } \\
\text { degustar diferentes vasos } \\
\text { con agua, mezclados con } \\
\text { otras sustancias (limón, } \\
\text { naranja, sal, cola-cao...). }\end{array}$ & $\begin{array}{l}\text { Experimentar, } \\
\text { pensar, } \\
\text { preguntarse. } \\
\text { (Adaptación de } \\
\text { la rutina de } \\
\text { pensamiento } \\
\text { ver, pensar, } \\
\text { preguntarse). }\end{array}$ & $\begin{array}{l}\text {-Observar de cerca y } \\
\text { describir qué hay } \\
\text { ahí. } \\
\text {-Construir } \\
\text { explicaciones e } \\
\text { interpretaciones. } \\
\text {-Establecer } \\
\text { conexiones. } \\
\text {-Razonar con } \\
\text { evidencia. } \\
\text {-Preguntarse y hacer } \\
\text { preguntas. }\end{array}$ \\
\hline $\begin{array}{l}\text { Sesión 2: a } \\
\text { Gotín le gusta } \\
\text { mojar los } \\
\text { objetos. }\end{array}$ & $\begin{array}{l}\text { Identificación } \\
\text { del grado de } \\
\text { absorción/imper } \\
\text { meabilidad del } \\
\text { agua en los } \\
\text { objetos. }\end{array}$ & $\begin{array}{l}\text { Se introduce en un } \\
\text { barreño rellenado de agua, } \\
\text { varios objetos como } \\
\text { diferentes tipos de } \\
\text { papeles, esponjas, bayetas, } \\
\text { algodón, telas, etc. }\end{array}$ & $\begin{array}{l}\text { Experimentar, } \\
\text { pensar, } \\
\text { preguntarse. }\end{array}$ & $\begin{array}{l}\text { Mismos } \\
\text { movimientos de } \\
\text { pensamiento que en } \\
\text { la sesión } 1 .\end{array}$ \\
\hline $\begin{array}{l}\text { Sesión 3: ¿De } \\
\text { qué manera } \\
\text { podemos ver a } \\
\text { Gotín? Los } \\
\text { estados del } \\
\text { agua. }\end{array}$ & $\begin{array}{l}\text { Reconocimiento } \\
\text { de los tres } \\
\text { estados del agua. }\end{array}$ & $\begin{array}{l}\text { A partir de un cubito de } \\
\text { hielo, el alumnado } \\
\text { manipula y vivencia la } \\
\text { trasformación de los tres } \\
\text { estados del agua. }\end{array}$ & $\begin{array}{l}\text { Experimentar, } \\
\text { pensar, } \\
\text { preguntarse. }\end{array}$ & $\begin{array}{l}\text { Mismos } \\
\text { movimientos de } \\
\text { pensamiento que en } \\
\text { la sesión } 1 .\end{array}$ \\
\hline $\begin{array}{l}\text { Sesión } 4 \text { : } \\
\text { aprendemos el } \\
\text { ciclo del agua } \\
\text { de una manera } \\
\text { experimental. }\end{array}$ & $\begin{array}{l}\text { Reconocimiento } \\
\text { de fenómenos } \\
\text { naturales del } \\
\text { ciclo del agua. }\end{array}$ & $\begin{array}{l}\text { Se representa el ciclo del } \\
\text { agua dentro de una bolsa } \\
\text { hermética. }\end{array}$ & $\begin{array}{l}\text { El titular } \\
\text { (E1 alumnado } \\
\text { puede elegir en } \\
\text { escribir un } \\
\text { titular o hacer } \\
\text { un dibujo que } \\
\text { capte la esencia } \\
\text { de la sesión). }\end{array}$ & $\begin{array}{l}\text {-Observar de cerca y } \\
\text { describir qué hay } \\
\text { ahí. } \\
\text {-Establecer } \\
\text { conexiones. } \\
\text {-Tener en cuenta } \\
\text { diferentes puntos de } \\
\text { vista y perspectivas. } \\
\text {-Captar lo esencial. }\end{array}$ \\
\hline $\begin{array}{l}\text { Sesión 5: } \\
\text { Gotín y sus } \\
\text { amigas las } \\
\text { arenas. }\end{array}$ & $\begin{array}{l}\text { Exploración de } \\
\text { los diferentes } \\
\text { tipos de } \\
\text { filtración del } \\
\text { agua según sea el } \\
\text { terreno. }\end{array}$ & $\begin{array}{l}\text { Se vierte dentro de un } \\
\text { embudo diferentes tipos } \\
\text { de arenas. }\end{array}$ & El titular. & $\begin{array}{l}\text { Mismos } \\
\text { movimientos de } \\
\text { pensamiento que en } \\
\text { la sesión } 4 \text {. }\end{array}$ \\
\hline $\begin{array}{l}\text { Sesión 6: } \\
\text { flotamos o no } \\
\text { flotamos. }\end{array}$ & $\begin{array}{l}\text { Identificación } \\
\text { del grado de } \\
\text { flotabilidad de } \\
\text { los objetos en el } \\
\text { agua. }\end{array}$ & $\begin{array}{l}\text { Se introducen varias veces } \\
\text { en un barreño rellenado } \\
\text { de agua hasta la mitad de } \\
\text { su capacidad, diferentes } \\
\text { objetos, comprobando su } \\
\text { flotabilidad. }\end{array}$ & $\begin{array}{l}\text { Antes pensaba, } \\
\text { ahora pienso. }\end{array}$ & $\begin{array}{l}\text {-Construir } \\
\text { explicaciones e } \\
\text { interpretaciones. } \\
\text {-Observar de cerca y } \\
\text { describir qué hay } \\
\text { ahí. } \\
\text {-Establecer } \\
\text { conexiones. } \\
\text {-Razonar con } \\
\text { evidencia. }\end{array}$ \\
\hline $\begin{array}{l}\text { Sesión 7: lluvia } \\
\text { ácida. }\end{array}$ & $\begin{array}{l}\text { Valoración de las } \\
\text { consecuencias de } \\
\text { la lluvia ácida. }\end{array}$ & $\begin{array}{l}\text { Se cuida y atiende durante } \\
\text { tres semanas, plantas } \\
\text { regadas con agua y plantas } \\
\text { regadas con lluvia ácida. }\end{array}$ & $\begin{array}{l}\text { Antes pensaba, } \\
\text { ahora pienso. }\end{array}$ & $\begin{array}{l}\text { Mismos } \\
\text { movimientos de } \\
\text { pensamiento que en } \\
\text { la sesión } 6 \text {. }\end{array}$ \\
\hline $\begin{array}{l}\text { Sesión 8: } \\
\text { limpiamos el } \\
\text { agua. }\end{array}$ & $\begin{array}{l}\text { Valoración de la } \\
\text { purificación y } \\
\text { accesibilidad a } \\
\text { conseguir agua. }\end{array}$ & $\begin{array}{l}\text { Cada discente se } \\
\text { construye su propio limpia } \\
\text { aguas (purificador de } \\
\text { agua). }\end{array}$ & E1 titular. & $\begin{array}{l}\text { Mismos } \\
\text { movimientos de } \\
\text { pensamiento que en } \\
\text { la sesión } 4 \text {. } \\
\end{array}$ \\
\hline
\end{tabular}




\section{Instrumentos y procedimiento}

Se han utilizado principalmente tres instrumentos que van a permitir apreciar la visibilidad del pensamiento y el grado de aprendizaje en nuestros estudiantes a lo largo del proceso.

Como instrumento principal de obtención de datos se han utilizado rúbricas específicas para evaluar los movimientos de pensamiento en cada una de las rutinas implementadas (García, Cañas y Pinedo 2017). La segunda herramienta utilizada ha sido las frases/dibujos realizados por los alumnos en la rutina el titular. Y para finalizar, destacar la utilización de un cuaderno de campo del maestro donde se han ido reflejando peculiaridades, anécdotas o datos llamativos de las sesiones.

A continuación se detalla en qué consisten cada uno de los instrumentos utilizados para la obtención de datos.

- Rúbricas específicas para evaluar los movimientos de pensamiento de cada tipo de rutina utilizada

A partir del trabajo de García et al. (2017) se han obtenido unas rúbricas específicas que evalúan la presencia o no presencia de los movimientos de pensamiento desarrollados a través de la realización de diferentes rutinas de pensamiento en el aula.

El objetivo de la rúbrica aquí planteada es "analizar la presencia y adecuación de los diferentes movimientos que caracterizan un pensamiento profundo en las tareas y actividades que realiza el alumnado en el aula" (García et al., 2017. p.238).

Del trabajo de García et al. (2017) se han seleccionado tres rúbricas de evaluación correspondientes a las tres rutinas de pensamiento elegidas para llevar a cabo en el aula: veo-pienso-me pregunto, el titular y antes pensaba ahora pienso (ver anexo I).

Una vez identificadas las tres rúbricas específicas, se han adaptado a los objetivos de este estudio, al área de conocimiento (ciencias experimentales), a las características del alumnado y sobre todo a la etapa de educación infantil, generando una rúbrica de evaluación para cada una de las sesiones realizadas teniendo en cuenta los movimientos de pensamiento a desarrollar en cada tipo de rutina.

Para finalizar, el docente realiza una heteroevaluación individual a los estudiantes a través de una rúbrica específica diseñada para cada sesión, el método de obtención de datos se basa en la observación directa. En estos organizadores gráficos se encuentran identificados los diferentes movimientos de pensamiento definidos por Ritchhart et al. (2014) en una escala de tres niveles donde se concreta el logro obtenido por los estudiantes: no se ha conseguido, nivel de logro medio, máximo nivel de logro (ver anexo I).

- Frases o dibujos realizados por los alumnos en la rutina el titular

Como se puede apreciar en la tabla 4 correspondiente a las sesiones de aprendizaje, en tres de ellas se ha llevado a cabo la rutina de pensamiento "el Titular" de Ritchhart et al. (2014). En esta rutina se le pedía al alumnado realizar una frase o un dibujo donde reflejara la idea fundamental obtenida en las sesiones de aprendizaje. A través de la elaboración del titular y de las explicaciones realizadas por los discentes en la exposición de los mismos, se aporta al alumnado otro medio para visibilizar su pensamiento.

- Cuaderno de campo

Para poder conseguir un análisis de los resultados adquiridos más reales y propios de una intervención educativa, se ha decidido utilizar como herramienta de obtención de datos el cuaderno de campo docente. Como manifiesta Albert (2007), este instrumento permite recoger peculiaridades, momentos destacables, conversaciones, anécdotas, propuestas de mejora, ....., lo que permite tener una visión realista y argumentada de los resultados obtenidos. 


\section{RESUltados: ANÁlisis de LA EVOLUCIÓN DE LOS MOVIMIENTOS DE PENSAMIENTO A TRAVÉS DE LAS RÚBRICAS ESPECÍFICAS}

A continuación se presenta un análisis de los resultados obtenidos en las rúbricas de evaluación específicas diseñadas para cada sesión de aprendizaje (ver anexo I). Se muestra la evolución que han tenido los alumnos en la consecución de cada movimiento de pensamiento a lo largo de las ocho sesiones de aprendizaje.

\section{Movimiento de pensamiento: observar de cerca y describir qué hay ahí}

En líneas generales en la consecución del movimiento de pensamiento observar de cerca y describir qué hay ahí, se han obtenido unos resultados positivos (ver figura 3). Esto es debido a que el alumnado era el responsable de manipular y desarrollar la actividad experimental así como de verbalizar lo que estaba ocurriendo en cada momento. Constantemente los docentes motivaban a los alumnos en el desarrollo de la actividad científica para que estos describieran qué estaba sucediendo en cada momento.

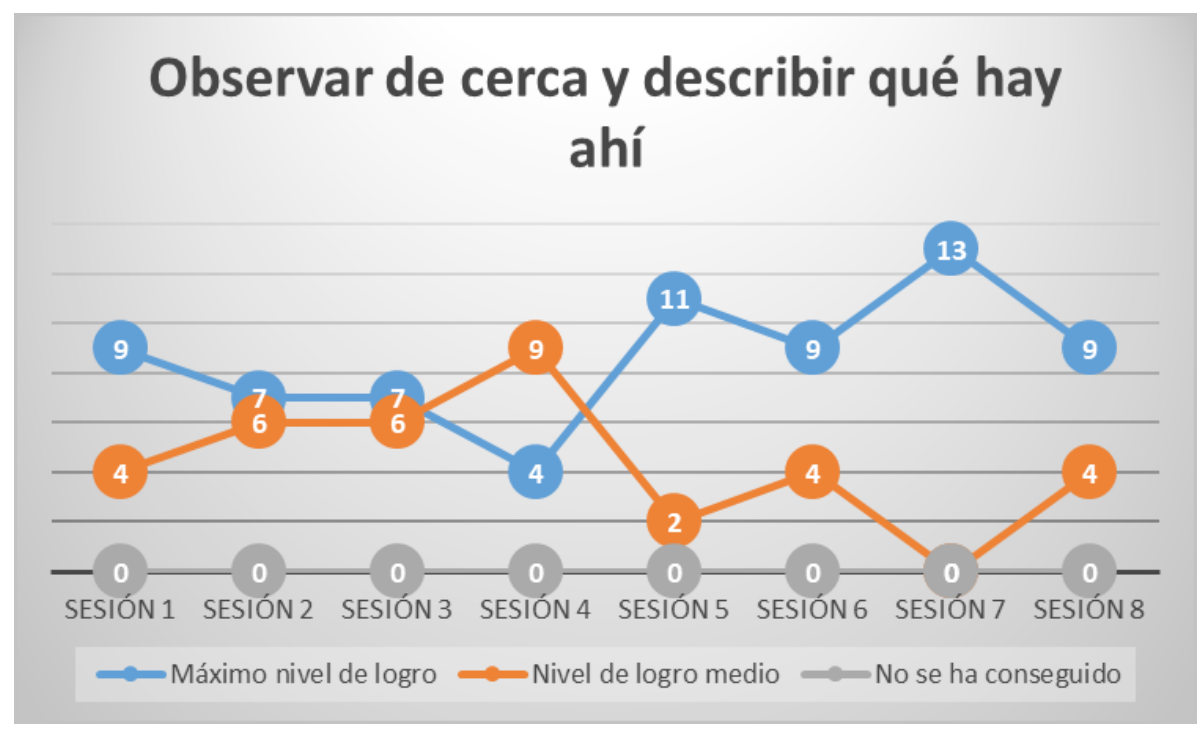

FIGURA 3

Movimiento de pensamiento observar de cerca y describir qué hay ahí.

Gráfico de líneas elaboración propia

En la figura 3 se puede apreciar cómo en todas las sesiones el alumnado se encuentra entre el nivel de logro medio y el máximo. Se ha podido comprobar que en las sesiones donde el contenido principal es más complejo y abstracto les resulta más difícil de describir (sesión 4 donde se trabaja el ciclo del agua).

Un dato muy significativo es que ningún alumno se ha encontrado en el nivel "no se ha conseguido". Por lo que se considera que las actividades experimentales y manipulativas llevadas a cabo fomentan que el niño describa de forma constante lo que está ocurriendo y le permita adquirir una base en su pensamiento que a su vez favorece el desarrollo del resto de movimientos de pensamiento en la propia rutina.

Ejemplo de evidencia práctica: en la sesión 2 en la que se trabaja el grado de absorción e impermeabilidad de los objetos con el contacto del agua, el alumnado describía la experimentación utilizando expresiones como: las esponjas y las bayetas guardan el agua, el algodón y las telas guardan agua, pero menos que la esponja o el agua se resbala en el papel de aluminio. 


\section{Movimiento de pensamiento: construir explicaciones e interpretaciones}

Este movimiento de pensamiento se ha reflejado en las sesiones donde se han llevado a cabo las rutinas de pensamiento veo-pienso-me pregunto y antes pensaba-ahora pienso.

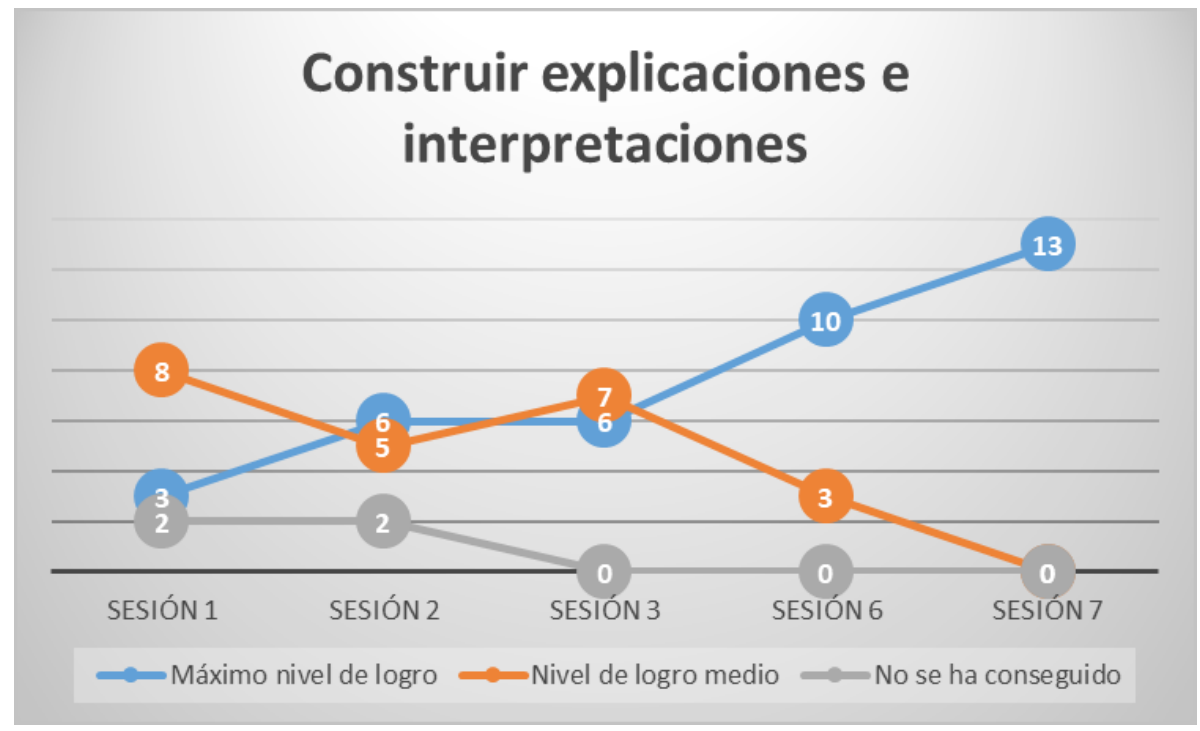

FIGURA 4

Movimiento de pensamiento construir explicaciones e interpretaciones Gráfico de líneas elaboración propia.

Se puede comprobar en la figura 4 cómo ha existido una evolución muy importante en la consecución del máximo nivel de logro por los alumnos sesión a sesión. Además, se aprecia cómo a partir de la sesión número 3 no ha existido ningún alumno que no haya generado alguna interpretación o explicación en el desarrollo de la intervención didáctica.

El alumnado de educación infantil tiene una gran capacidad imaginativa y de creación, por lo que este movimiento de pensamiento ha fomentado que el niño genere una gran variedad de hipótesis en todas las sesiones. El que los niños adquirieran el rol de científicos y tuvieran que buscar la solución al problema que les plantea Gotín fomentó que comenzaran a conocer de forma sencilla y simple el método científico.

Ejemplo de evidencia práctica: el máximo nivel de logro de este movimiento de pensamiento fue en la sesión número 7 , donde en un primer lugar los niños crearon multitud de interpretaciones de qué iba a suceder con las plantas regadas con lluvia ácida antes de la experimentación. Ejemplos como va a mutar y convertirse en una planta enorme y fuerte, otra interpretación fue que iba a convertirse en una planta carnívora, otros dedujeron que iba a perder las hojas y las flores, e incluso hicieron interpretaciones como que la planta iba a morir.

\section{Movimiento de pensamiento: establecer conexiones}

Sobre este movimiento de pensamiento se ha hecho mucho hincapié en el desarrollo de todas las sesiones, debido a que como explican Gómez et al. (2019) es de vital importancia que los alumnos establezcan conexiones entre la sesión de aprendizaje científica y los aprendizajes previos vividos en su entorno más cercano. 


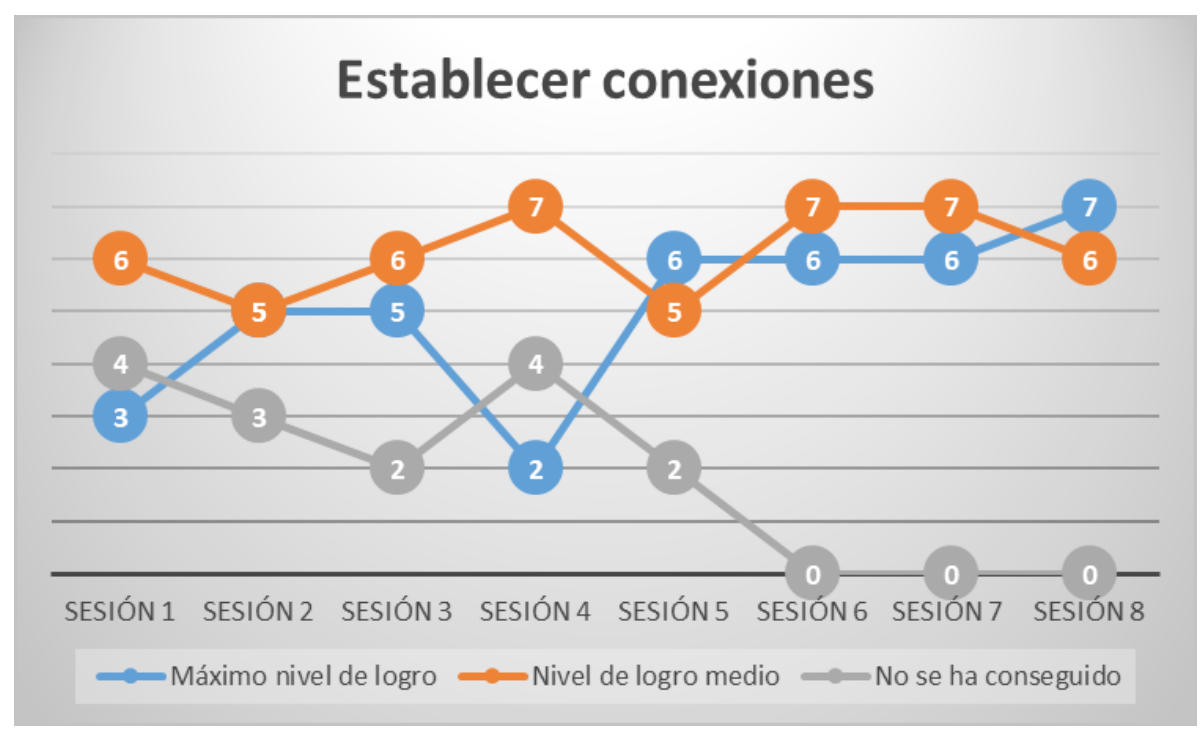

FIGURA 5

Movimiento de pensamiento establecer conexiones.

Gráfico de líneas elaboración propia.

En la figura 5 podemos apreciar cómo ha existido cierta evolución progresiva en la adquisición de este movimiento de pensamiento por parte del alumnado, donde el máximo nivel logro ha sido conseguido por un mayor número de alumnos conforme avanzaban las sesiones. Mientras que de nuevo a excepción de la sesión 4, ha disminuido progresivamente la no presencia de este movimiento de pensamiento.

También es relevante decir que cuanto más era conocido el contenido principal de la sesión, mayor era el establecimiento de conexiones con aprendizajes previos. Por este motivo en la sesión 4 se justifica la ausencia de este movimiento, debido a que se trabaja el ciclo del agua y es un tema poco conocido por el alumnado.

Cabe destacar que en las cuatro últimas sesiones han surgido multitud de conexiones entre los contenidos trabajados en cada sesión y aprendizajes previos vividos por el alumnado en su entorno más cercano.

Ejemplo de evidencia práctica: los alumnos establecieron conexiones en la sesión 5 por ejemplo, explicaron que muchos vasos, garrafas y cubiertos estaban hechos con arcilla para poder almacenar el agua (con la arcilla no se sale el agua del vaso y por eso podemos beber), también aportaron que el agua de la tierra de cultivo se filtra en una gran medida, para que todas las plantas pudieran absorber el agua (esta tierra es buena para las plantas, porque cogen mucha agua y asi pueden beber más fácil). Y por último que los tejados de las casas están hechos de arcilla para que cuando llueva, el agua no pueda entrar a nuestras viviendas (los tejados son marrones y naranjas, están bechos de arcilla, por eso no puede entrar el agua a mi casa por arriba).

\section{Movimiento de pensamiento: razonar con evidencia}

Este movimiento de pensamiento se ha encontrado muy presente en todo momento y en constante progresión. Como se puede apreciar en la figura 6 , a excepción de casos puntuales la mayoría de los niños se han encontrado entre el nivel medio y máximo de logro en todas las sesiones. 


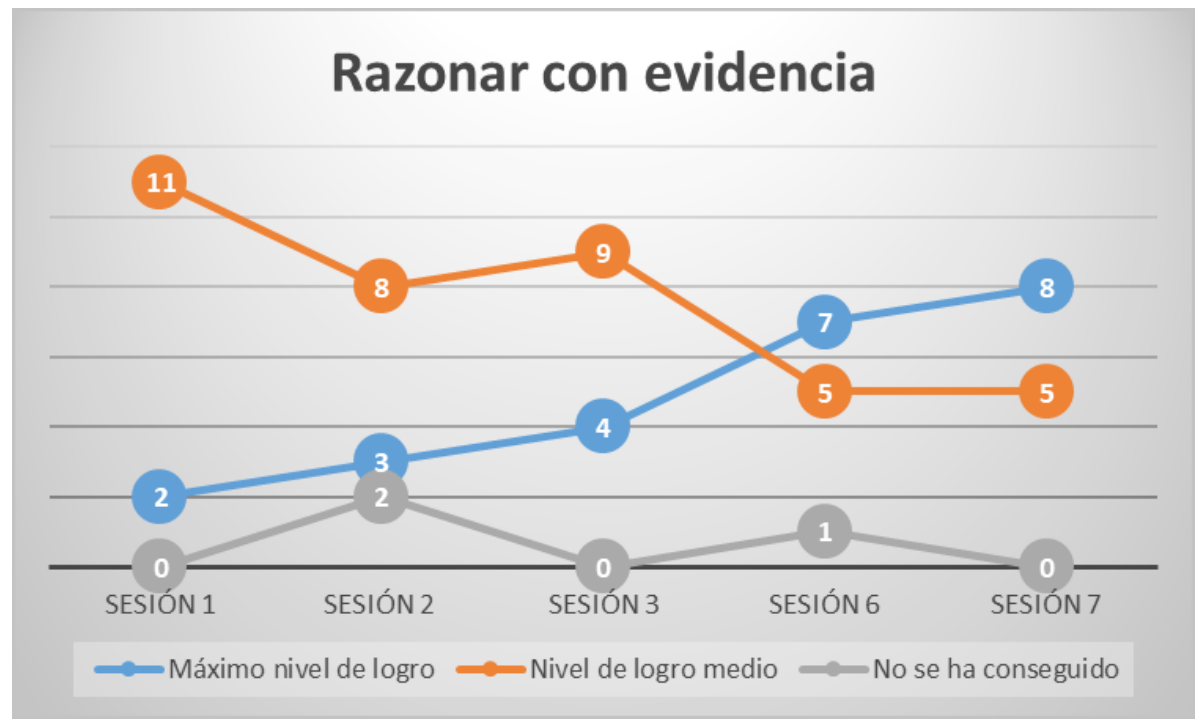

FIGURA 6

Movimiento de pensamiento razonar con evidencia.

Gráfico de líneas elaboración propia.

Esto ha sido posible gracias a que el alumnado a medida que avanzaban las sesiones ha aprendido que para razonar y justificar con evidencia lo que ocurría era necesario basarse en los sucesos sucedidos en la actividad experimental. Los niños han encontrado en los experimentos científicos utilizados una fuente de razonamiento que ha permitido que justificaran los sucesos o dieran respuesta de forma experimental a las preguntas planteadas por el docente o por sus iguales.

Ejemplo de evidencia práctica: en la propia experimentación científica en la sesión 1, los niños razonaban con constantes evidencias comparando recipientes. Por ejemplo, la mayoría del alumnado espontáneamente utilizaban sus sentidos, sobre todo el del gusto para probar el contenido. Seguidamente realizaban argumentaciones como este vaso tiene zumo de naranja, porque es de color naranja y huele a naranja o este vaso solo tiene agua, porque no sabe a nada y es transparente o que salado está este vaso, tiene mucha sal.

\section{Movimiento de pensamiento: preguntarse y hacer preguntas}

Este movimiento únicamente se ha trabajado en las tres primeras sesiones, en la rutina de pensamiento veopienso-me pregunto. Sin lugar a dudas el preguntarse y hacerse preguntas ha sido de los movimientos que más dificultad ha mostrado para que el alumnado pudiera hacer visible su pensamiento. 


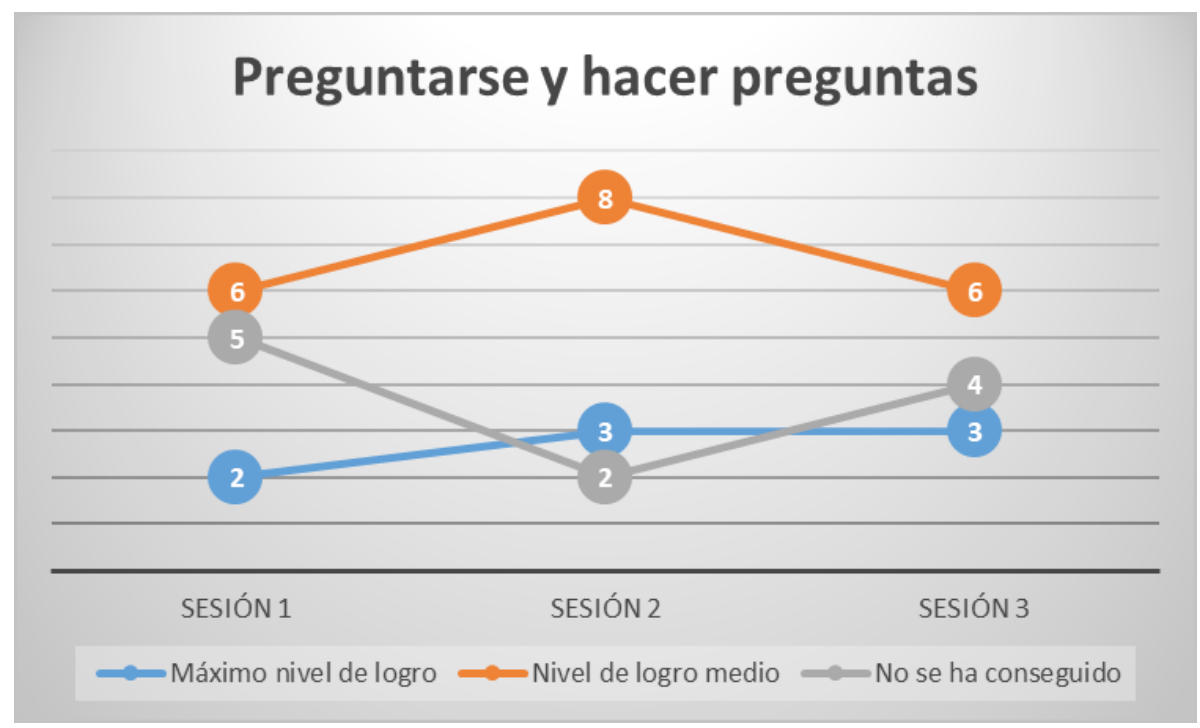

FIGURA 7

Movimiento de pensamiento preguntarse y hacer preguntas. Gráfico de líneas elaboración propia.

Podemos apreciar en la figura 7 que en las tres sesiones de aprendizaje existen alumnos que no han conseguido realizar preguntas y hacerse preguntas. Además de comprobar como en todas las sesiones hay una cantidad mayor de alumnos en el nivel de logro medio que en el máximo.

Dentro de la rutina de pensamiento veo-pienso-me pregunto, existen los pasos de pensar y de preguntarse. Varios de nuestros alumnos han mostrado dificultades en diferenciar el momento de pensar y el momento de preguntarse, debido a que lo interpretaban como un momento único. Provocando sobre todo en las sesiones 1 y 3 que cinco y cuatro alumnos respectivamente, no realizaran ninguna pregunta en relación con los contenidos trabajados.

En base al análisis de los resultados se deduce que este movimiento de pensamiento hay que trabajarlo con una mayor insistencia y concreción dentro del aula, desarrollando esta rutina de pensamiento u otras que permitan que el alumno haga preguntas y se pregunte a sí mismo.

Ejemplo de evidencia práctica: en la sesión 3 que se centraba en los estados del agua, las preguntas más frecuentes que surgieron fueron como iría Gotín vestido (gaseoso, líquido o sólido) si se encontrara en diferentes lugares de la tierra, del universo o de lugares fantasiosos. ¿Cómo iría Gotín vestido si estuviera en las nubes? ¿Y en el rio?, ¿Cómo iría Gotín vestido en el desierto? ¿Y dónde viven los pingüinos?, ¿Gotín iría vestido gaseoso en la Luna? ¿ ¿ Gotín cómo iría vestido en Hogwarts?

\section{Movimiento de pensamiento: tener en cuenta diferentes puntos de vista y perspectivas}

Como valoración general, podemos apreciar que la consecución del movimiento de pensamiento tener en cuenta diferentes puntos de vista y perspectivas ha ido en constante progresión. 


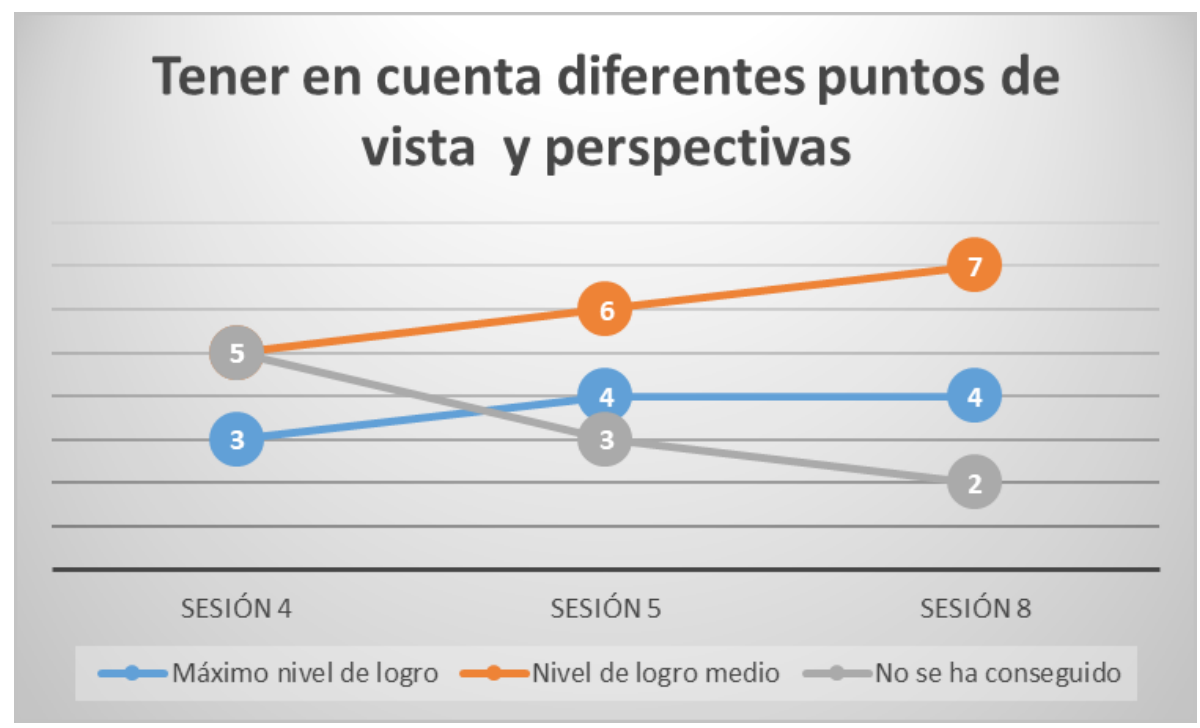

FIGURA 8

Movimiento de pensamiento tener en cuenta diferentes puntos de vista y perspectivas. Gráfico de líneas elaboración propia.

En la figura 8 podemos apreciar una evolución progresiva en la consecución de este movimiento de pensamiento, tanto en el máximo nivel de logro (en una menor medida) como en el nivel de logro medio (en una mayor medida), en contraposición de una reducción progresiva de estudiantes que no han conseguido presentar este movimiento de pensamiento a lo largo de las tres sesiones.

Ha sido curioso cómo los alumnos han tenido en cuenta los diferentes puntos de vista y perspectivas de sus compañeros dependiendo de la situación planteada en el aula. En el momento que el alumnado debía de resolver el problema planteado con ayuda del resto de sus compañeros para llevar a cabo la experimentación científica, sí que se ha podido apreciar el desarrollo de este movimiento de pensamiento. Mientras que en los momentos de compartir el pensamiento como en la explicación y presentación de los diferentes titulares, varios niños no atendían ni tenían en cuenta la explicación de sus compañeros.

Por lo tanto, el haber llevado a cabo actividades experimentales donde los alumnos tenían que colaborar, dialogar y ponerse de acuerdo, ha permitido que el alumnado tuviera en cuenta diferentes perspectivas y puntos de vista de personas afines a ellos.

\section{Movimiento de pensamiento: captar lo esencial}

Originariamente este movimiento de pensamiento tiene por nombre captar lo esencial y llegar a conclusiones, pero se ha decidido adaptar este movimiento a nuestros alumnos de educación infantil. Para ello se ha simplificado, centrándose únicamente en que el alumnado identifique las ideas esenciales, siendo estas los contenidos principales marcados en cada una de las sesiones de aprendizaje. 


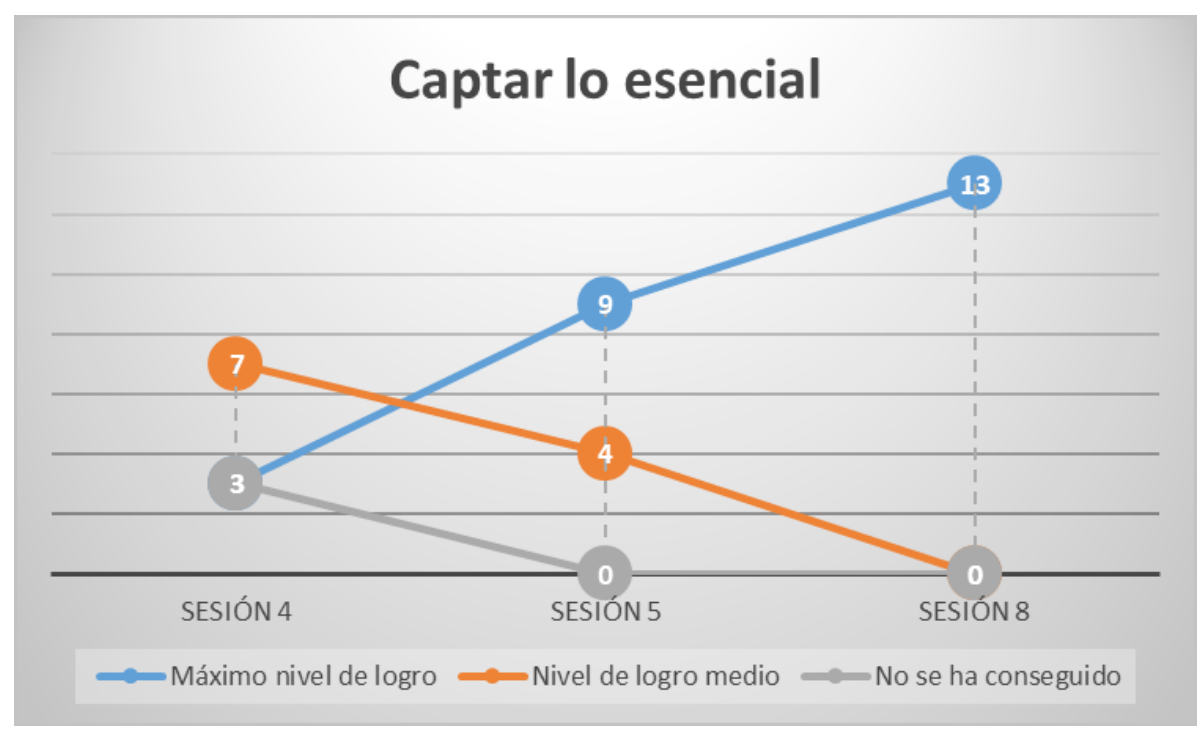

FIGURA 9

Movimiento de pensamiento captar lo esencial. Gráfico de líneas elaboración propia.

En la figura 9 se aprecia una evidente progresión en la adquisición por parte de nuestros alumnos en captar al menos la idea esencial de cada sesión de aprendizaje. Una evidencia se muestra en la evolución ejercida desde la sesión 4 en la que tan sólo 3 alumnos consiguen el máximo nivel de logro, mientras que en la sesión 8 alcanzaron la totalidad del alumnado el nivel máximo. Asimismo, en la sesión 3 cuatro alumnos no consiguieron captar la ideal principal de la sesión, mientras que en las sesiones 5 y 8 todos los alumnos captaron al menos algunas ideas esenciales de las sesiones de aprendizaje.

Ejemplo de evidencia práctica sesión 4 el ciclo del agua: en la presentación de los diferentes titulares pudimos apreciar como varios niños verbalizaban los tres procesos del estado del agua, utilizando sus propias expresiones. Como, por ejemplo el sol llama al agua para que suba hasta las nubes (evaporación), viajan en las nubes (condensación) y luego cae lluvia desde la nube hasta el suelo (precipitación) o el sol coge el agua del mar y lo sube a las nubes, guarda a Gotín en la nube y luego cae al mar (ver titular figura 10).

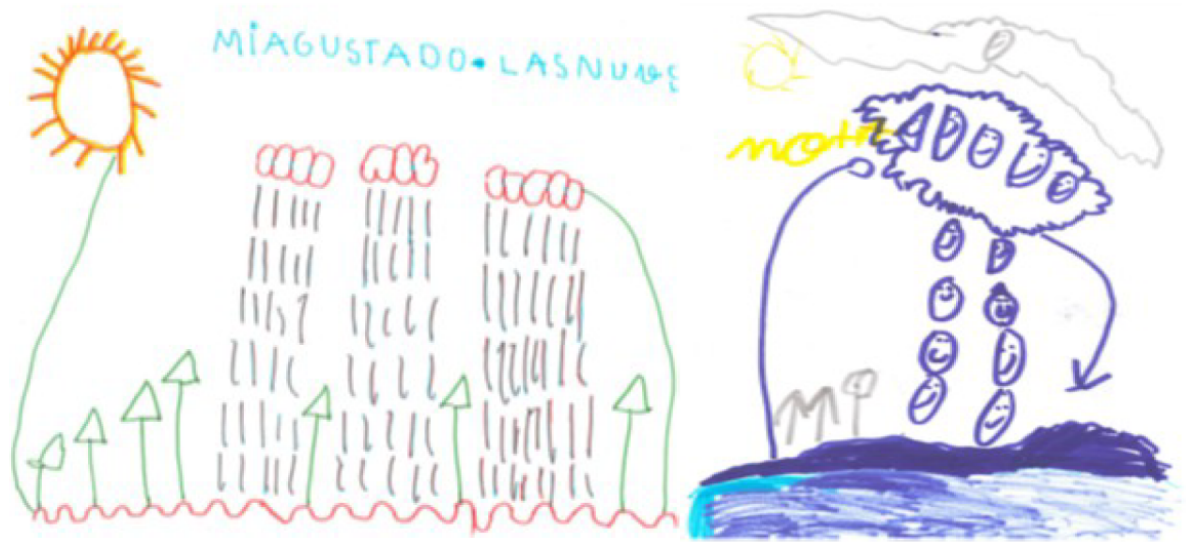

FIGURA 10

Titular ciclo del agua

Elaboración propia

Ejemplo de evidencia práctica sesión 8 (limpiamos el agua): se ha podido apreciar cómo los alumnos consiguieron el máximo nivel de logro en la consecución de este movimiento, debido a que la mayoría de ellos 
valoraron en la explicación de sus titulares y dibujos la necesidad de tener agua potable para poder vivir. En la figura 11 se pueden apreciar algunos ejemplos de titulares y dibujos realizados por los niños.

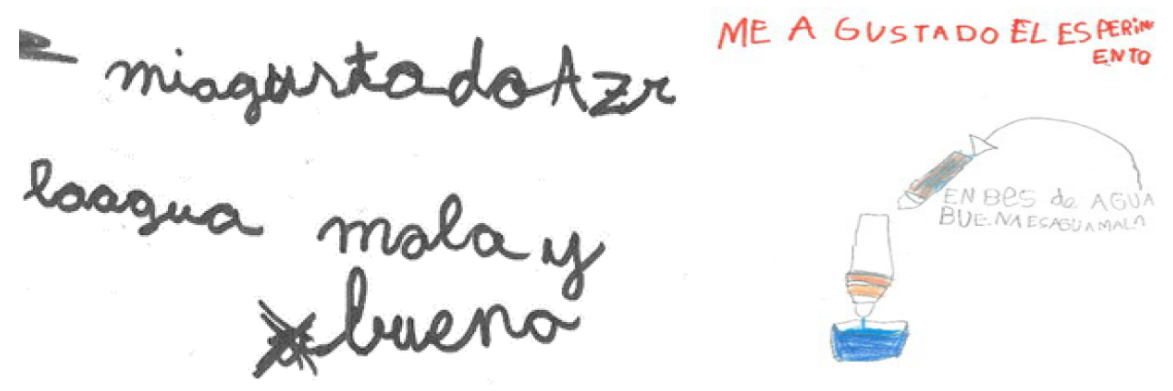

FIGURA 11

Titulares/dibujos sesión 8

Elaboración propia

\section{A MODO DE CONCLUSión}

El haber combinado los dos factores fundamentales de nuestra propuesta como son la didáctica de las ciencias experimentales y el pensamiento visible, ha hecho que nuestro alumnado visibilice su pensamiento a través del desarrollo de los diferentes movimientos trabajados en la experimentación científica.

Asimismo, que esta intervención didáctica se haya contextualizado en la temática del conocimiento y concienciación del cuidado del agua, ha permitido que nuestro alumnado adquiriera nuevos aprendizajes relacionados con el conocimiento de su entorno más cercano guiados por la consecución de los diferentes movimientos de pensamiento a la hora de razonar, describir, captar lo esencial, establecer conexiones, construir interpretaciones etc., en el mero desarrollo de la experimentación científica. Por ello entendemos que este tipo de propuestas didácticas que relacionan el pensamiento visible y las ciencias experimentales son perfectamente aplicables para abordar contenidos de ciencias en educación infantil.

En cuanto a la utilización de las rutinas de pensamiento, se ha comprobado a la hora de diseñar y llevar a cabo esta propuesta didáctica el gran grado de adaptabilidad y compatibilidad que tiene la interrelación de las ciencias experimentales con las diferentes rutinas de pensamiento utilizadas. A pesar de que se componen de unos pasos estructurados y organizados, permiten instaurar y adaptar cualquier tipo de recurso, gracias a que son procesos muy generales, sencillos y afines a conseguir cualquier objetivo didáctico que como docentes podamos plantear.

Otro aspecto fundamental que se concluye con el desarrollo de este trabajo, es que al existir una gran variedad de rutinas de pensamiento se considera fundamental saber elegir qué tipo de rutina utilizar para conseguir aquellos objetivos didácticos que se quieren alcanzar y movimientos de pensamiento a desarrollar en el alumnado.

La adecuada elección de cada tipo de rutina de pensamiento ha conseguido que la didáctica de las ciencias experimentales se llevara a cabo de una manera más propicia. En los siguientes ejemplos se puede apreciar este hecho: la rutina "veo-pienso-me pregunto" ha sido de gran utilidad para iniciar la propuesta didáctica y generar actitudes propias de la experimentación científica en nuestro alumnado; seguidamente llevar a cabo la rutina "el titular" ha proporcionado que el alumnado organizara sus ideas y aprendiera los conocimientos esenciales de cada sesión de aprendizaje y por último, la rutina de pensamiento "antes pensaba ahora pienso" ha permitido que el alumnado diera un paso más y adquiera de manera simplificada estrategias y actitudes propias del método científico como generar pequeñas hipótesis, verificar o refutar ideas, obtener resultados, llegar a conclusiones etc. 
Por ello, gracias a la aplicación de las rutinas de pensamiento y la consecución de los diferentes movimientos de pensamiento seleccionados, nuestro alumnado de educación infantil ha sido capaz de dar visibilidad a su pensamiento a través del aprendizaje de las ciencias experimentales.

Por último, para dar una prospectiva de futuro a este trabajo se presentan alternativas de mejora:

a) Desarrollar esta intervención didáctica en diferentes y variados contextos educativos para poder así comparar y discernir los resultados obtenidos en cada caso.

b) Generar programas de concienciación y formación en pensamiento visible y rutinas de pensamiento a maestros de todas las etapas educativas pero con un mayor énfasis a docentes de educación infantil.

c) Continuar elaborando trabajos en los que se relacionen la didáctica de las ciencias experimentales y las rutinas de pensamiento tanto en la etapa de educación infantil, como en etapas educativas superiores.

Para concluir, se espera que este trabajo sea de gran ayuda a maestros en activo como a futuros maestros con el fin de mejorar en su formación docente, valorando la necesidad de hacer visible el pensamiento del alumnado y el enseñar a pensar desde edades tempranas. Además de poder comprender cómo a través de las ciencias experimentales se pueden enseñar diferentes conocimientos de forma lúdica, manipulativa, motivante y cercana al entorno de nuestro alumnado.

\section{Materiales SUPlementarios}

Anexo I (pdf)

\section{Agradecimientos}

Agradecer a cada uno de los componentes del PID en Pensamiento Visible y nuevas tecnologías en los Grados de Educación de la Universidad de Valladolid (UVa), por hacernos conscientes de la vital importancia de enseñar a pensar a nuestro alumnado. Y también, al departamento de la didáctica de las Ciencias Experimental de la UVa, del campus María Zambrano de Segovia, por enseñarnos constantemente los grandes beneficios educativos y didácticos de las ciencias experimentales.

\section{REFERENCIAS}

Albert M. J. (2007) La investigación educativa. Claves teóricas. Madrid: McGraw-Hill.

Aymerich M. I., Puig N. S., y Blanch M. E. (1999). Fundamentación y diseño de las prácticas escolares de Ciencias Experimentales. Enseñanza de las ciencias: Revista de investigación y experiencias didácticas, 17(1), 45-59.

Brions E., y Gómez A. (2016) Psicología para docentes. Guía y casos resueltos aplicando el Aprendizaje Basado en Problemas (ABP). Madrid: Pirámide.

Cabell M. J. (2011) Ciencia en educación infantil: La importancia de un "rincón de observación y experimentación" o "de los experimentos" en nuestras aulas. Revista aula magna 10, 58-63.

Decreto 122/2007, de 27 de diciembre, por el que se establece el currículo del segundo ciclo de la Educación Infantil en la Comunidad de Castilla y León. Boletín oficial de Castilla y León. Miércoles, 2 de enero de 2008, n. 1, pp 6-16.

García N., Cañas M., y Pinedo R. (2017) Métodos de evaluación de rutinas de pensamiento: Aplicaciones en diferentes etapas educativas. En Núñez J.C., Gázquez J.J., Pérez-Fuentes M.C., Molero M., Martos A., Barragán A.B. y Simón M.M. (Ed.), Temas actuales de investigación en las áreas de la Salud y la Educación (pp.237-243). Almería: ASUNIVEP.

Gómez I.M., Rubiano E., y Gil P. (2019) Manual para el desarrollo de la metodología activa y el pensamiento visible en el aula. Madrid: Pirámide. 
Morales M. Y., y Restrepo I. (2015) Hacer visible el pensamiento: Alternativa para una evaluación para el aprendizaje. Infancias Imágenes 14(2), 89-100.

Perkins D. N. (2008) La escuela inteligente. Del adiestramiento de la memoria a la educación de la mente. Barcelona: Gedisa.

Perkins D. N. (1997) Una cultura donde el pensamiento sea parte del aire. Revista Zona Educativa 15, 39-41.

Perkins D. N. y Tishman, S. (2001) Dispositional aspects of intelligence. En S. Messick y J.M. Collis (ED.), Intelligence and personality: Bridging the gap in theory and measurement (pp. 233-257). New Jersey: Erlbaum.

Ritchhart R. (2015) Creating cultures of thinking. San Francisco: Jossey-Bass.

Ritchhart R., Church M., y Morrison K. (2014) Hacer visible el pensamiento. Cómo promover el compromiso, la comprensión y la autonomía de los estudiantes. Buenos Aires: Paidós.

Ritchhart R., Churc, M., y Morrison K. (2011) Making Thinking Visible. How to Promote Engagement Understanding, and Independence for All Learners. John Wiley \& Sons.

Ritchhart R., y Perkins D. N. (2008) Making thinking visible. Educational Leadership 65 (5), 57-61.

Salmon A. (2015) El desarrollo del pensamiento en el niño para escuchar, hablar, leer y escribir. Leer Escribiry Descubrir 2(1), 2-12.

Salmon A. (2009) Hacer visible el pensamiento para desarrollar la lectoescritura: Implicaciones para estudiantes bilingües, Lectura y vida. Revista latioamericana de lectura 30(4), 62-69.

Sarradelo L. (2012) Aprender a pensar: Iniciación en el entrenamiento de destrezas y rutinas de pensamiento con niños de 5 años. Logroño. Universidad Internacional de La Rioja. Recuperado de: https://reunir.unir.net/bitstream/han dle/123456789/839/2012_09_11_TFG_ESTUDIO_DEL_TRABAJO.pdf?sequence=1\&isAllowed=y

Swartz R., Costa A., Beyer B., Reagen R., y Kallick B. (2015) Aprendizaje Basado en el Pensamiento: Cómo desarrollar en los alumnos las competencias del siglo XXI. Madrid: SM.

Tishman S., y Plamer P. (2005) Visible thinking. Leadership Compass 2(4), 1-4.

Tishman S., Perkins D. N., y Jay E. (1994) Un aula para pensar. Aprender y enseñar en una cultura de pensamiento. Buenos Aires: Aique.

Torp L., y Sage S. (1999) El aprendizaje basado en problemas: Desde el jardin de infantes hasta el final de la escuela secundaria. Buenos Aires: Amorrortu editores.

Vega S. (2012) Ciencia 3-6 Laboratorios de ciencias en la escuela infantil. Barcelona: Graó.

\section{INFORMACIÓN ADICIONAL}

Para citar este artículo: Gil, C. y Manso-Bartolomé, A. (2022) Visibilizar el pensamiento a través de la enseñanza de las ciencias experimentales en Educación Infantil. Revista Eureka sobre Enseñanza y Divulgación de las Ciencias 19(1), 1201.doi:10.25267/Rev_Eureka_ensen_divulg_cienc.2022.v19.11.1201 